\title{
Lipohypertrophy due to HAART: a case series
}

\author{
Arikeri Vasu Deva Rao*, Samarasimha Reddy L., Srinivas Velupula, Jayababu N., \\ Imran Khan, Kiran Kumar M.
}

Department of Pharmacology, Kakatiya Medical College, Warangal 506007, Telangana, India

Received: 31 May 2018

Accepted: 26 June 2018

\section{*Correspondence to:}

Dr. Arikeri Vasu Deva Rao, Email: arikerivasudevarao@ gmail.com

Copyright: (C) the author(s), publisher and licensee Medip Academy. This is an openaccess article distributed under the terms of the Creative Commons Attribution NonCommercial License, which permits unrestricted noncommercial use, distribution, and reproduction in any medium, provided the original work is properly cited.

\begin{abstract}
A subset of HIV-1 infected patients undergoing Highly Active Antiretroviral Therapy (HAART) develops a lipodystrophy syndrome. It is characterised by loss of subcutaneous adipose tissue (face, limbs and buttocks) visceral fat accumulation and lipomatosis especially in dorsocervical area. In addition these patients show metabolic alteration implicative of metabolic syndrome particularly dyslipidaemia and insulin resistance. These alterations lead to enhanced cardiovascular risk and favour the development of diabetes in such patients. A complex combination of HIV infection, drug treatment related events and lipotoxicity appears to contribute to the development of lipodystrophy syndrome. Active lipolysis in subcutaneous fat combined with impaired storage capacity in subcutaneous depot leads to ectopic deposition of lipids either in visceral or in non-adipose sites. Lipotoxicity, a pathogenic factor in the lipodystrophy syndrome should be considered in the strategies for treating and /or preventing the morphological alterations and systemic metabolic disturbances associated with lipodystrophy.
\end{abstract}

Keywords: HAART, Lipodystrophy

\section{INTRODUCTION}

The introduction of HAART a combination of different ant-i retroviral agents/drugs has vastly improved the health states of HIV-1 infected patients. ${ }^{1}$ Viral Drug components of HAART include NRTI, NNRTI and PI's are inhibitors of viral reverse transcriptase in relation to their chemical nature and mechanism of action. ${ }^{2}$

Approximately $40-50 \%$ of HIV infected patients under HAART show alteration in adipose tissue distribution (lipodystrophy) in association with systemic metabolic complications which constitutes HIV-1 associated Lipodystrophy Syndrome (HALS). ${ }^{3}$ It includes lipoatophy, lipohypertrophy and mixed lipodystrophy. ${ }^{4}$ Lipoatophy is characterised by any one of the following alterations i.e., Fat loss in the face, fat loss in the buttocks, fat loss from legs, fat loss in arms or disclosure of veins in the muscles of both the limbs. Similarly, Lipohypertrophy is characterised by abdominal obesity, breast hypertrophy in women, increase fat at the side of the neck, increased fat at back of the neck, dorsocevical (Buffalo hump) and suprapubiclipomas. $^{5,6}$ Mixed lipodystrophy is a combination of lipoatophy and lipohypertrophy. ${ }^{7}$

India has the third largest HIV epidemic in the world. In 2016, HIV prevalence in India was estimated to be $0.3 \%$ which equates to 2.1 million patients living with HIV and 62000 people died due to AIDS related illness. ${ }^{8,9}$ Central fat accumulations is more frequent in females which are associated with increased body fat and poor diet quality. ${ }^{10}$ 


\section{CASE REPORT}

\section{Case 1}

A 23 year old female patient with height $154 \mathrm{~cm}$ and body weight $45 \mathrm{~kg}$ was diagnosed as sero positive for HIV with CD4+ count 68 cells $/ \mathrm{mm}^{3}$ with no $\mathrm{HBV} / \mathrm{HCV}$ coinfections and was graded as WHO clinical stage II. She was started with TLN regimen and continued till June 2017.Then she changed to TLE regimen with median base line $\mathrm{CD}^{+}$count 1020 cells $/ \mathrm{mm}^{3}$. She had $10 * 9 \mathrm{~cm}$ diffuse non-tender, fluctuant and non-reducible swelling over the nape of the neck. Her hormonal levels and serum chemistry was normal.

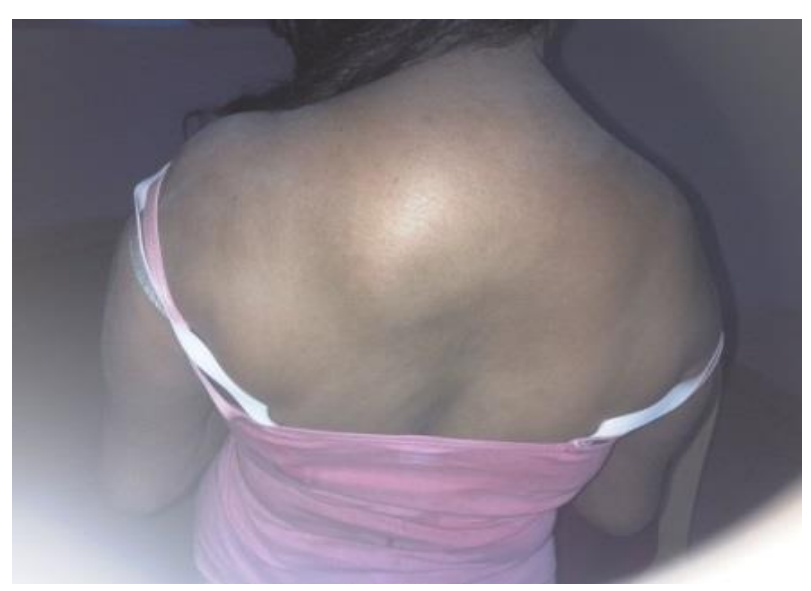

Figure 1: Buffalo hump.

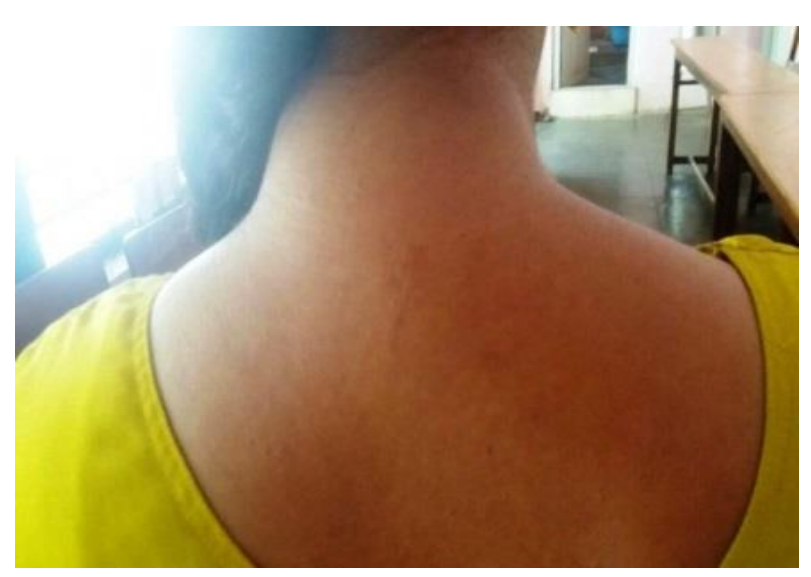

Figure 2: Lipohypertropy over the neck.

\section{Case 2}

A 21 year old female patient with height $159 \mathrm{~cm}$ and body weight $38 \mathrm{~kg}$ was diagnosed as sero positive for HIV with $\mathrm{CD} 4+$ count 162 cells $/ \mathrm{mm}^{3}$ with no $\mathrm{HBV} / \mathrm{HCV}$ coinfections and was graded as WHO clinical stage II. She was started with ZLN regimen continued till February 2011. Patient developed anaemia (Hb-6.8gm\%) and underwent 4 units of whole blood transfusions. Then she changed to SLN regimen continued till May 2013 and was changed to LAN regimen due raised liver enzymes. She is currently graded as WHO clinical stage T2 with median base line $\mathrm{CD}^{+}$count 970 cells $/ \mathrm{mm}^{3}$. She had $2 * 4 \mathrm{~cm}$ diffuse non-tender and non-reducible swelling over the nape of the neck. Her hormonal levels and serum chemistry is normal.

\section{Case 3}

A 20 year old female patient with height $162 \mathrm{~cm}$ and body weight $38 \mathrm{~kg}$ was diagnosed as sero positive for HIV with CD4+ count 224 cells $/ \mathrm{mm}^{3}$ in February 2007 with no $\mathrm{HBV} / \mathrm{HCV}$ co-infections and was graded as WHO clinical stage II. She was started with ZLN regimen continued till date with median base line CD4+ count 1080 cells $/ \mathrm{mm}^{3}$. She had $2 * 2 \mathrm{~cm}$ diffuse non-tender and non-reducible swelling over the nape of the neck. Her hormonal levels and serum chemistry is normal.

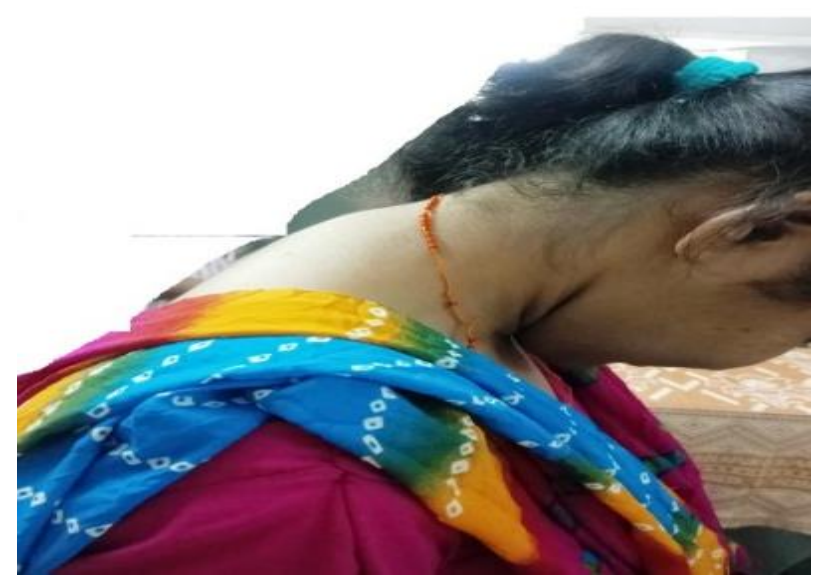

Figure 3: Lipohypertropy (case 3).

Case 4

A 18 year old female patient with height $150 \mathrm{~cm}$ and body weight $36 \mathrm{~kg}$ was diagnosed as sero positive for HIV with $\mathrm{CD}^{+}$count 182 cells $/ \mathrm{mm}^{3}$ in June 2007 with no $\mathrm{HBV} / \mathrm{HCV}$ co-infections and was graded as WHO clinical stage II. She was started with ZLN regimen continued till January 2011. Patient developed myalgia and was changed to ZLE regimen. She developed red maculo Papular rash associated with itching and burning sensation over the extremities after 10 days. Regimen was discontinued and was changed to SLN continuing till date. Her median base line CD4+ counts 900 cells $/ \mathrm{mm}^{3}$. She had $5 * 6 \mathrm{~cm}$ diffuse non-tender and non-reducible swelling over the nape of the neck. Her hormonal levels and serum chemistry is normal.

\section{Case 5}

A 40 year old female patient with height $160 \mathrm{~cm}$ and body weight $49 \mathrm{~kg}$ was diagnosed as sero positive for HIV with CD4+ count 194 cells $/ \mathrm{mm}^{3}$ in November 2007 with no $\mathrm{HBV} / \mathrm{HCV}$ co-infections and was graded as WHO clinical stage II. She was started with ZLN regimen continued till date with median base line $\mathrm{CD} 4^{+}$count $1358 \mathrm{cells} / \mathrm{mm}^{3}$. 
She had $4 * 7 \mathrm{~cm}$ diffuse non-tender and non-reducible swelling over the nape of the neck. Her hormonal levels and serum chemistry is normal.

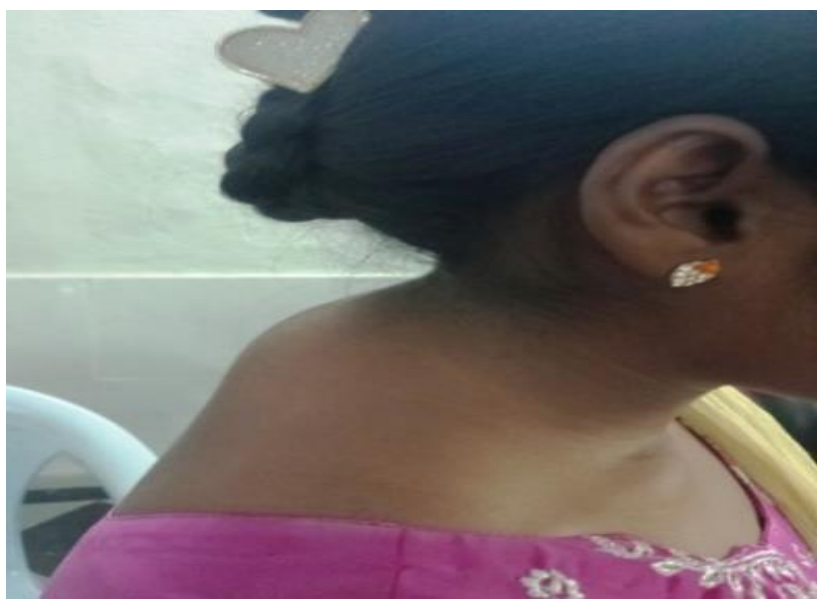

Figure 4: Lipohypertropy (case 4).

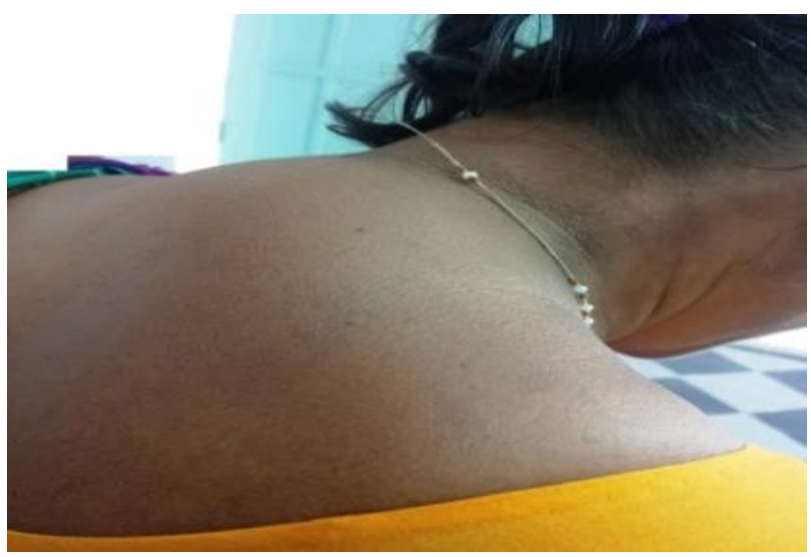

Figure 5: Lipohypertropy (case 5).

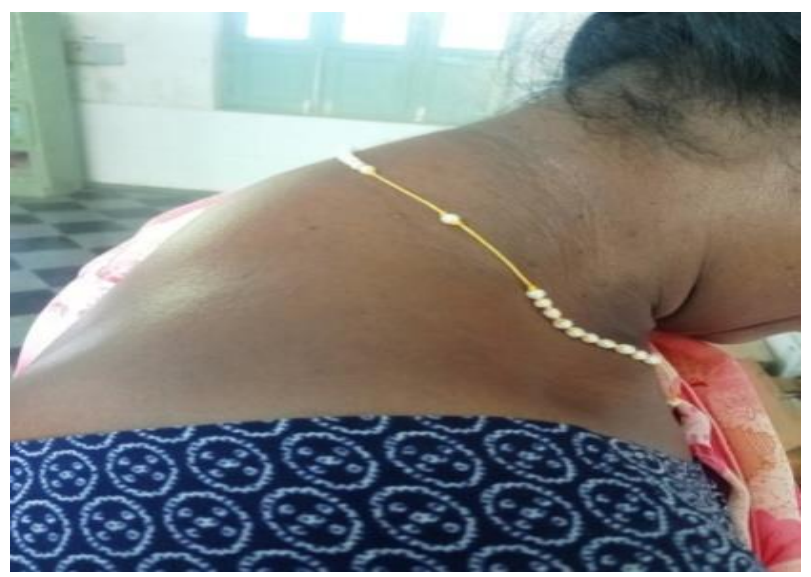

Figure 6: Lipohypertropy (case 6).

\section{Case 6}

A 38 year old female patient with height $155 \mathrm{~cm}$ and body weight $45 \mathrm{~kg}$ was diagnosed as sero positive for HIV with $\mathrm{CD} 4+$ count 186 cells $/ \mathrm{mm}^{3}$ in with no $\mathrm{HBV} / \mathrm{HCV}$ co- infections and was graded as WHO clinical stage II. She was started with ZLN regimen continued till date with median base line $\mathrm{CD}^{+}$count $1185 \mathrm{cells} / \mathrm{mm}^{3}$. She had $2 * 3 \mathrm{~cm}$ diffuse non-tender and non-reducible swelling over the nape of the neck. Her hormonal levels and serum chemistry is normal.

\section{DISCUSSION}

The pathogenesis of HALS has been linked with alterations in various metabolic and morphological parameters. Host factors (e.g.: female sex), markers of HIV infection (HIV viral load and nadir CD4+count) duration and type of ART are associated with lipohypertrophy. ${ }^{11}$ Protease inhibitors have been most cited in the development of lipohypertrophy and abdominal perimeter tend to increase after initiation of ART regardless of the type of regimen. ${ }^{12,13}$

Use of NRTIs appears to be associated with fat wasting aspects of HALS. The deleterious effects of NRTIs, especially thymidine analogues are attributed to their interference with mitochondrial DNA polymerase $-\gamma$. Inhibition of mitochondrial DNA polymerase $-\gamma$ leads to progressive mitochondrial DNA depletion and subsequent mitochondrial dysfunction, called as mitochondrial toxicity. ${ }^{14}$ Mitochondrial dysfunction induced specifically by thymidine analogues (Stavudine, zidovudine) found to have increased expression of adipogenic transcription factors in abdominal subcutaneous tissue and decreased expression in thigh suggesting that ART may have tissue specific effects leading to lipoatophy, lipohypertrophy or a combination of both. ${ }^{15}$

NNRTI, Efavirenz, may be more closely associated with fat wasting with its powerful anti-adipogenic effect in cultured adipose cells. ${ }^{16}$ Central fat hypertrophy in HALS patients relates to TNF- $\alpha$ circulating levels and waist circumference. ${ }^{17}$ In HIV linked Buffalo Hump and Brown Adipose Tissue (BAT) hypertrophy patients, abnormal brown fat like cells with no therapeutic properties are present. These cells retain the highly proliferative capacity of brown adipocyte lineage leading to buffalo hump. ${ }^{18}$ Because of potential metabolic and cardiovascular risk posed by fat accumulation, there has been significant intent and research on treatment of HIV lipohypertrophy. ${ }^{19,20}$

Diet and lifestyle changes are typically well tolerated and confer health benefits, they are recommended in initial treatment approach to lipodystrophy. Lifestyle changes such as supervised aerobic training and exercise training programme demonstrated improvements in muscle strength, cardiorespiratory fitness, endurance and a reduction in waist circumference but no change in visceral adipose tissue. ${ }^{21}$ According to Sekhar et.al a defect in peripheral adipocytes results in the greater bioavailability of fatty acids in circulation which are selectively deposited in visceral adipose tissue resulting in higher lipid turnover and uptake. This cause of dysregulation could be related to 
the effects of HIV itself by HIV-1 accessory protein Vpr or the effects of specific antiretroviral agents. ${ }^{22}$ Leptin levels appear to correlate with body fat phenotype with lowest level seen in patients with lipoatophy and highest levels in patients with lipohypertrophy. In lipohypertrophy elevated leptin levels can be attributed to increased secretion of adipocytes and / or resistance at the receptor level. ${ }^{23}$ Metformin use has led to proportionate reduction in SAT, LAT and documented loss of limb fat in one study. Use of Metformin should be avoided in patients with concurrent lipoatophy. ${ }^{24}$

Surgical treatment includes liposuction of dorsocevical or surgical removal of adipose tissue. ${ }^{25}$ Lack of standard clinical definition and heterogeneous characterization of lipodystrophy pose challenges to examine the aetiologies and risk factors of lipoatophy, lipohypertrophy and mixed syndrome. ${ }^{26}$ Many studies had established the need for universal standardized methods to diagnose lipodystrophy syndromes, validated in both clinical and field settings to compare findings across the studies. ${ }^{27}$

Knowledge of adverse reactions to antiretroviral drugs is necessary especially taking into account the possibility of severe adverse effects. Clinicians play an important role in the management of adverse effects on HAART in HIV patients, should be familiar with the conditions and be prepared to handle them adequately.

\section{CONCLUSION}

The antiretroviral drugs used during early HAART era were largely associated with important metabolic effects, with a great potential to significantly decrease the quality of life of HIV patients and the ability to impair some of the gains resulting in HAART. The development of newer friendlier and safer ARV drugs minimised these problems in the patients receiving the therapy in late HAART era. Patients who were exposed to older drugs in the past were severely affected by these body changes with significant impact on their self-esteem and quality of life. Changing lifestyle, with adherence to adequate nutritional habits, physical exercise and some medical interventions demonstrated modest benefits. Surgical interventions are needed in extreme cases in order to mitigate the consequences of fat deposition/ atrophy. Prompt recognition, diagnosis, early identification and withdrawal of potential causative agents for the time being is the best that we can do for patients to most significantly influence the outcome of prognosis. Future studies on ART medication should have longer follow-ups to seek further evidences recurrence risk, long term safety profile, dosing regimen and suitable management of side effects in addition to benefits of HAART.

\section{ACKNOWLEDGEMENTS}

The authors are thankful to the staff and patients of HIV/ART Centre MGM hospital, Dr. AV Ramanaiah, Dr Mallesham and Dr. Usha (Medical officer), ART Centre
Mahatma Gandhi Memorial Hospital, Warangal, Telangana, Pharmacovigilance Centre, Department of Pharmacology, Kakatiya Medical College Warangal, Telangana function under National coordination Centre, Pharmacovigilance Program of India, Ghaziabad, India.

Funding: No funding sources

Conflict of interest: None declared

Ethical approval: The study was approved by the Institutional Ethics Committee

\section{REFERENCES}

1. Kumar O. Assessment of adverse drug reactions to antiretroviral agents among HIV patients. J App Pharmaceut Scien. 2018;8(02):079-82.

2. Bruton LL, Chabner BA, Knollman BC (Eds): Goodman and Gilman's The Pharmacological Basis of Therapeutics: 13 ${ }^{\text {th }}$ Ed: McGRAW-Hill, New York; 2018:1137-1157.

3. Villarroya F, Domingo P, Giralt M. Lipodystrophy in HIV 1-infected patients: lessons for obesity research. Int J Obesi. 2007 Dec;31(12):1763.

4. WHO. Patient evaluation and anti retroviral treatment for adults and adoloscents, clinical protocol for the WHO European Region; 2012. Available at: http://www.euro.who.int/_data/assets/pdf_file/0012/ 152013/e95794.pdf

5. Lana LG, Junqueira DR, Perini E, de Pádua CM. Lipodystrophy among patients with HIV infection on antiretroviral therapy: a systematic review protocol. BMJ open. 2014 Mar 1;4(3):e004088.

6. Gkrania-Klotsas E, Klotsas AE. HIV and HIV treatment: effects on fats, glucose and lipids. British Medical Bulletin. 2007 Nov 2;84(1):49-68.

7. Mercier S, Gueye NF, Council A, Frontbonne A, Copin N, N diaye I, et al. Lipodystrophy and metabolic disorders in HIV-1 infeected adults on 4-9-year antiretroviral therapy in Senegal: a case control study. J Acquir Immune Defic Syndr.2009:51(2):224-30.

8. UNAIDS; 2017. Data Book [pdf]. Available at: http://www.unaids.org/sites/default/files/media_asset/ 2017-Global-AIDS-Monitoring_en.pdf

9. Global AIDS monitoring. Indicators for monitoring the 2016 United Nations Political Declaration on HIV and AIDS. Geneva: UNAIDS; 2017:85.

10. Lopez- Dupla PJM, Alba V, Beltran-Debon R, Martinez E, Domingo P, et al. HIV/Antiretroviral therapy-related Lipodystrophy Syndrome (HALS) is associated with higher RBP4 and lower omentin in plasma. Clin Microbiol Infect. 2015.

11. Dube MP, Komarow L, Mulligan K. Longterm body fat outcomes in antiretroviral-naive participants randomized to nelfinavir or efavirenz or both plus dual nucleosides. Dual X-ray abssorptiometry results from A5005s, a substudy of Adult Clinical Trials G roup 384. J Acquir Immune Defic Syndr. 2007;45(5):50814. [PubMed :17589373].

12. Shikuma CM, Yang Y, Glesby MJ, Meyer III WA, Tashima KT, Ribaudo HJ, et al. AIDS Clinical Trials 
Group Protocol A5095 Study Team. Metabolic effects of protease inhibitor-sparing antiretroviral regimens given as initial treatment of HIV-1 Infection (AIDS Clinical Trials Group Study A5095). JAIDS. 2007 Apr 15;44(5):540-50.

13. Boyd MA, Carr A, Ruxrungtham K, Srasuebkul P, Bien D, Law M, et al. Changes in body composition and mitochondrial nucleic acid content in patients switched from failed nucleoside analogue therapy to ritonavir-boosted indinavir and efavirenz. The $\mathbf{J}$ Inf Diseas. 2006 Sep 1;194(5):642-50.

14. Katjung BG, Masrers SB, Trevor AJ (Eds). Basic and Clinical Pharmacology: $14^{\text {th }}$ Edition, Lange, McGraw Hills, New York; 2018:870-884.

15. Villarroya F, Domingo P, Giralt M. Lipodystrophy associated with highly active anti-retroviral therapy for HIV infection: the adipocyte as a target of antiretroviral-induced mitochondrial toxicity. Trends in Pharmacological Sciences. 2005 Feb 1;26(2):88-93.

16. Kratz M, Purnell JQ, Breen PA, Thomas KK, Utzschneider KM, Carr DB, et al. Reduced adipogenic gene expression in thigh adipose tissue precedes human immunodeficiency virus-associated lipoatrophy. The J Cli Endocrinol \& Metaboli. 2008 Mar 1;93(3):959-66.

17. David E. Golan, Ehrin J Armstrong, April W. Armstrong Eds: Principles of Pharmacology: The pathological basis of disease: $4^{\text {th }}$ Ed, Lippincott Williams and Wilkins, Philadelphia; 2017:705-717.

18. Caron-Debarle M, Lagathu C, Boccara F, Vigouroux C, Capeau J. HIV-associated lipodystrophy: from fat injury to premature aging. Trends in molecular medicine. 2010 May 1;16(5):218-29.

19. Perez-Matute P, Perez-Martinez L, Blanco JR, Oteo JA. Role of mitochondria in HIV infection and associated metabolic disorders: focus on nonalcoholic fatty liver disease and lipodystrophy syndrome. Oxidative medicine and cellular longevity. $2013 \mathrm{Jul}$ 21;2013.

20. Tadesse TW, Mekonnen BA, Tesfaye TY. Self repoted adverse drug reactions and their influence on highly active antiretroviral therapy in HIV infected patients: a cross sectional study. BMC Pharmacology and Toxicology. 2014;15:32.

21. Gomes- Neotn M, Conceicao CS, Oliveira Carvalho $\mathrm{V}$, Brites C. A systematic review of effects of different types of $\mathrm{n}$ therapeutic exercise on physiologic and functional measurements in patients with HIV/AIDS. Clincs (Soo Paulo). 2013;68(8):1157-67.

22. Lichtenstein K, Balasubramanyam A, Sekhar R, Freedland E. HIV-associated adipose redistribution syndrome (HARS): definition, epidemiology and clinical impact. AIDS research and therapy. 2007 Dec;4(1):16.

23. Tiliscan C, Aramă V, Mihăilescu R, Munteanu DI, Streinu-Cercel A, Ion DA, et al. Leptin expression in HIV-infected patients during antiretroviral therapy. Germs. 2015 Sep;5(3):92.

24. Srinivasa S, Wong K, Fitch KV, Wei J, Petrow E, Cypess AM, et al. Effects of lifestyle modification and metformin on irisin and FGF 21 among HIV-infected subjects with the metabolic syndrome. Clinical endocrinology. 2015 May;82(5):678-85.

25. Lipodystrophy syndrome in HIV. Brazil. Ministry of Health. 2011. Available at: http://www.aids.gov.br/sites/default/files/publica/201 1/50427/vers_o_final_63134.pdf. Accessed July 9, 2014.

26. Mercier S, Gueye NF, Cournil A, Fontbonne A, Copin $\mathrm{N}$, Ndiaye I, et al. Lipodystrophy and metabolic disorders in HIV-1-infected adults on 4- to 9yearantiretroviral therapy in Senegal: a case-control study. J Acquir Immune Defic Syndr. 2009;51(2):22430 .

27. Cournil A, Coudray M, Kouanfack C, Essomba CN, Tonfack CA, Biwole'-Sida M, et al. Reduced dose of stavudine and lipoatrophy in HIV-infected patients in Cameroon. Antivir Ther. 2010;15(7):1039-43.

Cite this article as: Rao AVD, Reddy SL, Velupula S, Jayababu N, Khan I, Kumar KM. Lipohypertrophy due to HAART: a case series. Int J Basic Clin Pharmacol 2018;7:1662-6. 